\title{
Flame structure of a low-pressure laminar premixed and lightly sooting acetylene flame and the effect of ethanol addition
}

\author{
T. Bierkandt ${ }^{\mathrm{a}}$. T.Kasper ${ }^{\mathrm{a} *}$, E. Akyildiz ${ }^{\mathrm{a}}$, A. Lucassen ${ }^{\mathrm{b}}$, P. Oßwald ${ }^{\mathrm{c}}$, M. Köhler ${ }^{\mathrm{c}}$, P. Hemberger $^{\mathrm{d}}$ \\ ${ }^{a}$ University of Duisburg-Essen, Germany \\ ${ }^{b}$ Sandia National Laboratories, Livermore, California, USA \\ ${ }^{\mathrm{c}}$ DLR - Institute of Combustion Technology, Stuttgart 70569, Germany \\ ${ }^{\mathrm{d}}$ Molecular Dynamics Group, Swiss Light Source, Paul Scherrer Institut, Villigen CH 5232, Switzerland
}

Corresponding Author:

T. Kasper, Thermodynamics, Lotharstr. 1, 47057 Duisburg, Germany phone: +49-203-379-1854, fax: +49-203-379-1250 email: tina.kasper@uni-due.de

Colloquium Topic Area:

Laminar Flames

\begin{tabular}{|l|l|c|}
\hline \multicolumn{1}{|c|}{ Part } & \multicolumn{1}{c|}{ Method } & \# words \\
\hline Main text & Microsoft Word 2010 word count & 3495 \\
\hline Equations & $(0)$ lines $\times 7.6$ words/line & 0 \\
\hline References & $(43+2) \times 2.3$ lines/ref $\times 7.6$ words/line & 822 \\
\hline Tables & {$[(0+2) * 1+(+2) * 1+(+2)] \times 7.6$ words/line } & 0 \\
\hline Figure 1 & {$[(91 \mathrm{~mm}+10 \mathrm{~mm}) \times 2.2$ words $/ \mathrm{mm}]+31$} & 253 \\
\hline Figure 2 & {$[(91 \mathrm{~mm}+10 \mathrm{~mm}) \times 2.2$ words $/ \mathrm{mm}]+28$} & 250 \\
\hline Figure 3 & {$[(54 \mathrm{~mm}+10 \mathrm{~mm}) \times 2.2$ words $/ \mathrm{mm}]+24$} & 165 \\
\hline Figure 4 & {$[(92 \mathrm{~mm}+10 \mathrm{~mm}) \times 2.2$ words $/ \mathrm{mm}]+18$} & 242 \\
\hline Figure 5 & {$[(54 \mathrm{~mm}+10 \mathrm{~mm}) \times 2.2$ words $/ \mathrm{mm}]+28$} & 169 \\
\hline Figure 6 & {$[(54 \mathrm{~mm}+10 \mathrm{~mm}) \times 2.2$ words $/ \mathrm{mm}]+14$} & 155 \\
\hline Figure 7 & {$[(54 \mathrm{~mm}+10 \mathrm{~mm}) \times 2.2$ words $/ \mathrm{mm}]+21$} & 162 \\
\hline Figure 8 & {$[(54 \mathrm{~mm}+10 \mathrm{~mm}) \times 2.2$ words $/ \mathrm{mm}]+21$} & 162 \\
\hline Figure 9 & {$[(53 \mathrm{~mm}+10 \mathrm{~mm}) \times 2.2$ words $/ \mathrm{mm}]+23$} & 162 \\
\hline Figure 10 & {$[(53 \mathrm{~mm}+10 \mathrm{~mm}) \times 2.2$ words $/ \mathrm{mm}]+24$} & 163 \\
\hline Total & & $\mathbf{6 2 0 0}$ \\
\hline
\end{tabular}

Supplemental material has been included in the submission of this paper.

Submitted to the $35^{\text {th }}$ International Symposium on Combustion, San Francisco, CA, August 3-8, 2014. 
Flame structure of a low-pressure laminar premixed and lightly sooting acetylene flame and the effect of ethanol addition

T. Bierkandt, T.Kasper, E. Akyildiz, A. Lucassen, P. Oßwald, M. Köhler, P. Hemberger

\section{Abstract}

The flame structure of a fuel-rich $(\phi=2.4)$, laminar premixed, and lightly sooting acetylene flame at 40 mbar and the influence of ethanol addition on the species pool was investigated. Special emphasis was put on the analysis of important soot precursors like propargyl, benzene, and the polyynes. The mole fractions of more than 50 stable and radical species up to $\mathrm{m} / \mathrm{z}=170$ are obtained experimentally in the flames by molecular-beam mass spectrometry (MBMS) in combination with single-photon ionization (SPI) by vacuum ultraviolet (VUV) radiation from the Advanced Light Source (ALS) in Berkeley, CA, USA. For the neat acetylene flame, successful measurements were performed with a combination of MBMS and imaging photoelectron photoion coincidence spectrometry (iPEPICO) at the VUV beamline at the Swiss Light Source (SLS) in Villigen, Switzerland and add additional species information to the data set. Some interesting isomers $\left(\mathrm{C}_{3} \mathrm{H}_{2}, \mathrm{C}_{4} \mathrm{H}_{5}, \mathrm{C}_{4} \mathrm{H}_{2} \mathrm{O}\right)$ can be clearly identified by comparison of measured photoionization efficiency (PIE) curves or threshold photoelectron (TPE) spectra with Franck-Condon simulations or literature spectra, respectively. Because of apparatus improvements, the chemical resolution in this study goes beyond prior work and provides a highquality data set for the development of reaction mechanisms at fuel-rich, low-pressure conditions.

Keywords: acetylene flame structure; ethanol addition; VUV photoionization; threshold photoelectron spectroscopy; soot precursors 


\section{Introduction}

In times of increasing oil scarcity and rising fuel prices, the share of biofuels as a fuel substitute or additive grows continuously and bioethanol is one of the main fossil fuel substitutes [1]. Different fuels like acetylene [2], ethylene [3], benzene [4] and commercial gasoline [5] were used in previous studies under various conditions to investigate the effect of ethanol addition under fuel-rich conditions, which resulted each time in a diminution of the production of soot compared to the combustion of neat fuel. Here, the species $\mathrm{C}_{2} \mathrm{H}_{2}$ (acetylene), $\mathrm{C}_{3} \mathrm{H}_{3}$ (propargyl radical), $\mathrm{C}_{3} \mathrm{H}_{5}$ (allyl radical), and $\mathrm{C}_{6} \mathrm{H}_{6}$ (benzene) are of particular importance for the formation of polycyclic aromatic hydrocarbons (PAHs). The PAHs themselves play a key role for the formation of soot and their formation is described by the fuel-independent H-abstraction- $\mathrm{C}_{2} \mathrm{H}_{2}$-addition (HACA) mechanism according to Frenklach et al. [6]. Addition of acetylene to an aromatic radical leads to higher aromatics like naphthalene or phenanthrene. Acetylene itself is the dominant hydrocarbon in the exhaust gas of fuel-rich flames and therefore the most likely growth component. Depending on the fuel, other reactions of small hydrocarbons with aromatic compounds must be considered [7]. Polyynes $\left(\mathrm{C}_{2 \mathrm{n}} \mathrm{H}_{2}, n \geq 2\right)$, which are linear-chain hydrocarbon molecules, have a high reactivity in polymerization reactions and are associated with soot $[8,9]$.

Alternative oxygenated fuels like ethanol can provide, under certain conditions, a positive life-cycle assessment and thus environmental benefits particularly with regards to greenhouse-gas emissions reduction. Unfortunately, increased emissions of other toxic species like aldehydes are observed [10]. To control pollutant emissions, the corresponding chemical processes involved in combustion must be studied in well-controlled fundamental laboratory experiments. An established technique for species analysis in model flames is molecular-beam mass spectrometry.

Numerous fuel-rich acetylene flames with different stoichiometries have been investigated previously by molecularbeam mass spectrometry in combination with electron-impact ionization [11-14] but to our knowledge only twice with photoionization $[15,16]$. The experimental results can be used to improve kinetic models particularly the modeling of soot precursors and soot formation. Experimental data are compared to the state-of-the-art model of J.A. Miller (Argonne National Laboratory) to demonstrate satisfactory agreement, but efforts to gain fundamental new insights on acetylene chemistry from the comparison go beyond the scope of this experimental work. The fuel-rich acetylene flames considered here demonstrate the resolution of the new time-of-flight mass spectrometer at the ALS and the first results from a new flame system at the SLS. Furthermore, ethanol addition to the neat acetylene flame provides initial insights into the chemical changes induced in the intermediate species pool for a fuel with the one of the highest sooting propensities. 


\section{Experiment}

We measured two fuel-rich $\mathrm{C}_{2} \mathrm{H}_{2} / \mathrm{O}_{2} / \mathrm{Ar}(0.98 / 1.02 / 2.00)$ and $\mathrm{C}_{2} \mathrm{H}_{2} / \mathrm{C}_{2} \mathrm{H}_{5} \mathrm{OH} / \mathrm{O}_{2} / \mathrm{Ar}(0.873 / 0.097 / 1.03 / 2.00)$ flames with stoichiometries of $\phi=2.40$ at 40 mbar and a total gas flow of $4 \mathrm{slm}$. The acetylene flame had a C/O ratio of 0.96 . For the blended flame $10 \%$ of the acetylene is substituted by ethanol while stoichiometry, dilution and cold gas velocity are kept constant, so that the $\mathrm{C} / \mathrm{O}$ ratio was 0.90 . The flames are stabilized on 6.00-cm-diameter water-cooled McKenna burners and gases are regulated by calibrated mass flow controllers. Ethanol is metered liquid, vaporized [17], and added to the premixed gas stream at the ALS setup.

The MBMS setup at the Chemical Dynamics Beamline 9.02 at the ALS and the VUV beamline at the SLS are comparable and described in detail in [18] and [19], respectively. In addition, the mass spectrometer of the ALS setup has been upgraded and now features a new time-of-flight mass spectrometer (Kaesdorf) with mass resolution of $m / \Delta m \approx$ 1800 for $m / z=28$, which allows separation of some isobaric ions; e.g., CO and $\mathrm{C}_{2} \mathrm{H}_{4}$. Mass resolution at the SLS is $m / \Delta m$ $\approx 200$ for $\mathrm{m} / \mathrm{z}=28$ and thereby considerably worse than at the ALS because no reflectron is used. The iPEPICO detection scheme at the SLS allows the simultaneous measurement of photoionization mass spectra and velocity map images of electrons in coincidence, permitting measurement of mass-selected threshold photoelectron spectra (ms-TPES). Details can be found in [20,21]. The ms-TPES reflect unique state-specific transitions and yield a fingerprint of the molecules with a resolution that surpasses the resolution of photoionization efficiency curves measured at the ALS or SLS. Consequently, species identification of isomeric species can be performed with higher confidence at the SLS. In principle, the instrument at the SLS can provide independent quantitative data sets [19], but the focus of these first measurements was to supplement speciation information by TPES.

In order to achieve assignment of the different species and to create concentration profiles, two different measurements were conducted: A burner scan, where the ionization energy is constant and the burner position is changed, and an energy scan, where the position of the burner is stationary and the ionization energy is varied.

Procedures for the evaluation of species mole fractions follow Cool et al. [22]. The data-reduction procedures for the ALS system were further refined and a summary, including error discussion, can be found in [17]. Data reduction of the SLS mass spectra follows the same logic, and a description of the appropriate modifications can be found in [19].

\section{Results and Discussion}


Overall, we detected more than 50 intermediate species in the fuel-rich acetylene flame with the new mass spectrometer at the ALS and calculated their mole fraction profiles. This number of species is similar to [15]. Table S1 in the supplemental material gives details of the measured species at the ALS in the acetylene flame as well as the flame blended with ethanol and lists their maximum mole fractions with the corresponding burner positions. For the following discussion we will refer to Table S1 when maximum mole fractions are compared. Furthermore, a detailed compilation of all calculated mole fractions from measurements at the ALS system for both flames and the temperature profiles used for modeling are presented in the supplemental material. There are also figures of measured and modeled mole fraction profiles for some additional species. We have used the model of J.A. Miller, which was used successfully in previous studies [23,24], to verify the experimental data.

The experimental data show that for the intermediates with the largest concentrations, the maximum mole fractions in the mixed flame are lower than in the neat acetylene flame. This is especially true for the main soot precursors propargyl (1.18 times lower) and benzene (1.25 times lower), the polyynes, and some other hydrocarbons like $\mathrm{C}_{6} \mathrm{H}_{4}$ or $\mathrm{C}_{3} \mathrm{H}_{2}$. In contrast, the maximum mole fractions of oxygenated species like ketene $\left(\mathrm{C}_{2} \mathrm{H}_{2} \mathrm{O}\right)$ or acetaldehyde $\left(\mathrm{C}_{2} \mathrm{H}_{4} \mathrm{O}\right)$ and also the concentrations of allyl and methyl radicals are lower in the neat flame. If the only effect of ethanol addition is a replacement effect, the precursor concentrations will drop by a factor of $10 \%$ as seen in earlier work [25]. Any larger or smaller effect can be attributed to the ethanol. Eventually, the data are provided for mechanism validation, which should be able to capture changes in $\mathrm{C} / \mathrm{O}$ ratio and stoichiometry equally.

\section{Major species}

In Fig. 1, the experimental mole fraction profiles of the major species in the acetylene flame and the blended flame with $10 \%$ ethanol are presented and compared with the modeling results. Furthermore, the temperature profiles, which were used for the modeling, are mapped.

The experimental temperature profiles were determined from the temperature dependence of the sampling rate through the quartz nozzle, which means that the shape of the profile is derived from the argon mole fraction. The determination of a temperature profile in this way is afflicted with larger errors than a direct measurement but it has been shown that this procedure is a useful approximation for modeling MBMS data [26] that eliminates the need to shift simulated profiles. The temperature in the exhaust gas was set to $2000 \mathrm{~K}$ for the pure acetylene flame based on similar flames [12,15]. Also for the $\mathrm{C}_{2} \mathrm{H}_{2} / \mathrm{C}_{2} \mathrm{H}_{5} \mathrm{OH}$ flame, the exhaust gas temperature was set to be $2000 \mathrm{~K}$ because of the nearly identical adiabatic temperature in both flames. 
The experimental data for the reactants $\left(\mathrm{C}_{2} \mathrm{H}_{2}, \mathrm{O}_{2}, \mathrm{Ar}, \mathrm{C}_{2} \mathrm{H}_{5} \mathrm{OH}\right)$ and major products $\left(\mathrm{H}_{2}, \mathrm{H}_{2} \mathrm{O}, \mathrm{CO}, \mathrm{CO}_{2}\right)$ match in good approximation the simulated mole fractions predicted by the mechanism of J.A. Miller. Agreement for $\mathrm{H}_{2}$ and $\mathrm{H}_{2} \mathrm{O}$ mole fractions is nearly perfect and is within $15 \%$ for $\mathrm{CO}$ and $\mathrm{CO}_{2}$. Deviations are within the error limits of the main-species mole fractions (10-15\%). For the acetylene flame, oxygen and fuel are consumed more rapidly so that the main reaction zone is closer to the burner (about $1 \mathrm{~mm}$ ), and $\mathrm{H}_{2}$ and $\mathrm{H}_{2} \mathrm{O}$ exhaust concentrations are slightly lower than for the ethanoldoped flame. Acetylene is the most abundant hydrocarbon in the exhaust gas (similar concentration as $\mathrm{CO}_{2}$ ) and has a major influence on the formation of soot precursors.

Similar results are observed in the comparison of the experimental data and the calculated mole fractions for the major species in the acetylene flame measured at the SLS (Fig. S1, supplemental material). However, the concentration profile of $\mathrm{H}_{2}$ is somewhat lower and the $\mathrm{H}_{2} \mathrm{O}$ higher compared to the data obtained by PI-MBMS at the ALS and the simulation. Data reduction procedures for the SLS data are still in an early stage of development and have, for example, not taken experimental mass-discrimination-correction factors into account, which can account for some of the deviations. Overall, the experimental data for the pure acetylene flame give a satisfactorily consistent overview of the flame structure even though they were measured with different MBMS systems.

\section{Combustion intermediate species}

The propargyl radical $\left(\mathrm{C}_{3} \mathrm{H}_{3}\right)$, as a major benzene precursor molecule, is the most important species for soot formation and can be found under fuel-rich conditions with typical mole fractions of $10^{-3}-10^{-4}$. Its formation is based on the reaction of acetylene with singlet $\mathrm{CH}_{2}$ and to a minor extent with triplet $\mathrm{CH}_{2}[16,27]$. The measured signal intensity for $m / z=39$ from the energy scans fits the PIE curve from [28] very well for both systems (Fig. 2). Furthermore, the TPE spectrum of the propargyl radical recorded at $3.46 \mathrm{~mm}$ above the burner surface fits the intensity and position of the adiabatic ionization energy at $8.70 \mathrm{eV}$ obtained from a Franck-Condon simulation [29] very well and is also in agreement with previous experimental data [30]. Concentration of propargyl radicals directly affects the formation of benzene and phenyl due to the recombination reaction $\left(\mathrm{C}_{3} \mathrm{H}_{3}+\mathrm{C}_{3} \mathrm{H}_{3}=\mathrm{C}_{6} \mathrm{H}_{6}\right.$ or $\left.\mathrm{C}_{6} \mathrm{H}_{5}+\mathrm{H}\right)$ and reaction with the allyl radical $\left(\mathrm{C}_{3} \mathrm{H}_{5}\right)$. Both radical recombinations are important for the formation of $\mathrm{C}_{6}$ aromatic hydrocarbons and thus for the formation of PAHs [31].

In contrast, benzene formation through $\mathrm{C}_{2} \mathrm{H}_{2}$ and $n-\mathrm{C}_{4} \mathrm{H}_{3}$ or $n-\mathrm{C}_{4} \mathrm{H}_{5}$ [32] plays no significant role for the benzene production in acetylene flames [27] because of the low concentration of the $n$-isomers in comparison to the resonantly stabilized $i$-isomers [18]. Our measurements confirm that the dominant species in a fuel-rich acetylene flame is $i$ - $\mathrm{C}_{4} \mathrm{H}_{3}$ for $m / z=51$. For $m / z=53$ we could identify $i-\mathrm{C}_{4} \mathrm{H}_{5}$ clearly. Distinction between $\mathrm{CH}_{3} \mathrm{CCCH}_{2}$ and $\mathrm{CH}_{3} \mathrm{CHCCH}$ was not 6 
possible but a comparison of PIE spectra from measurements at the SLS system with previous work by Hansen et al. [33] shows, however, that either or both of these species are present as shown in Fig. 3.

Because the propargyl mole fraction is lower in the ethanol-doped than in the neat flame, the mole fraction of benzene should also be lowered by the addition of ethanol. The experimental data (1.25 times lower) as well as the modeling results (1.74 times lower) confirm this effect (Fig. 4). Benzene is the most abundant isomer in the acetylene flames, but fulvene can also be clearly identified by its onset near $8.36 \mathrm{eV}$ in the PIE spectrum. Its concentration was calculated to be about 7.5 times lower than benzene. Figure 5 demonstrates how well the integrated signal intensities of $\mathrm{m} / \mathrm{z}=78$ from the energy scan of the neat acetylene flame match the literature cross sections of fulvene [34] and the weighted sum of the fulvene and benzene [35] cross sections, respectively. The mole fraction profiles of some other aromatics (benzyne, toluene, phenol, phenylacetylene, naphthalene and indene) can also be obtained from the ALS data. Through recombination, the cyclopentadienyl radical $\left(\mathrm{C}_{5} \mathrm{H}_{5}\right)$ can lead directly to the formation of higher PAHs like $\mathrm{C}_{10} \mathrm{H}_{8}$ whereas formation of naphthalene is favored at low temperature and of fulvalene at high temperature [36]. PAHs with three or more condensed aromatic rings (e.g., phenanthrene and anthracene) could not be detected. The lack of higher PAHs in this slightly sooting flame leads to the assumption that the concentrations of these species are under the detection limit or that they play only a minor role for the formation of soot in acetylene flames and that the "acetylene route" [36], which indicates the formation of soot aerosols by chemical condensation of polyynes at high temperatures, is more favored.

The allyl radical could be detected in low concentration and can be clearly identified with the help of the threshold photoelectron spectrum. Figure 6 shows the TPES obtained from the measurements at the SLS in comparison with a spectrum measured by Schüßler et al. [38]. Both peaks, the vertical ionization energy at 8.133 eV and the cationic CCC bending mode $v_{7}^{+}$at $8.185 \mathrm{eV}$ are in good agreement with our data (8.139 and $8.189 \mathrm{eV}$, respectively). Other $\mathrm{C}_{3} \mathrm{H}_{5}$ isomers (e.g. 2-propenyl or cyclopropyl radical) could not be observed. The experimental peak mole fraction is 1.35 times higher in the flame blended with ethanol. This increase is in agreement with the modeling result, which also predicts a small increase of the peak concentration by the addition of ethanol. The main production path to form allyl is the reaction of $\mathrm{C}_{2} \mathrm{H}_{3}$ with the methyl radical [27]. The fact that the allyl radical concentration is higher in the ethanolblended flame implies another route for its formation. Thus, the reaction of singlet $\mathrm{CH}_{2}$ with $\mathrm{C}_{2} \mathrm{H}_{4}$ [3] or $\mathrm{C}_{3} \mathrm{H}_{6} \mathrm{with}_{\mathrm{CH}}$ to form $\mathrm{C}_{3} \mathrm{H}_{5}$ could play a relevant role due higher ethylene and propene concentrations. These reactions are also included in the chemical mechanism. The experimental as well as the simulated results show that the concentration of $\mathrm{CH}_{3}$ is higher for the flame with ethanol (about 1.45 times). The ethane concentration also increases through methyl radical recombination. 
The $\mathrm{C}_{3} \mathrm{H}_{2}$ isomers are important for $\mathrm{PAH}$ formation because they are in equilibrium with propargyl and form $\mathrm{C}_{4} \mathrm{H}_{5}$ by the reaction with methyl. They were studied in detail by Taatjes et al. [39], who observed propargylene and cyclopropenylidene in a rich cyclopentene flame. Figure 7 shows the PIE curve at $6.5 \mathrm{~mm}$ above the burner surface for the present fuel-rich acetylene flame. The curve has an onset at $8.9 \mathrm{eV}$, which coincides with the ionization potential of triplet propargylene. Comparison of the measured PIE spectrum with a Franck-Condon simulation of photoionization from triplet propargylene at $300 \mathrm{~K}$ from [39] reveals another $\mathrm{C}_{3} \mathrm{H}_{2}$ isomer with an IP about $9.15 \mathrm{eV}$. Hence, the best fit to the measured PIE spectrum is the sum of Franck-Condon simulations for photoionization from triplet propargylene (60\%) and cyclopropenylidene (40\%).

Polyacetylenes, so-called polyynes, are well-known [8] to be associated with soot. They appear at the end of the reaction zone and their chain growth occurs through reaction with acetylene $\left(\mathrm{C}_{2 n} \mathrm{H}+\mathrm{C}_{2} \mathrm{H}_{2}=\mathrm{C}_{2 n+2} \mathrm{H}_{2}+\mathrm{H}\right)$ or its radical $\mathrm{C}_{2} \mathrm{H}$ $\left(\mathrm{C}_{2 \mathrm{n}} \mathrm{H}_{2}+\mathrm{C}_{2} \mathrm{H}=\mathrm{C}_{2 \mathrm{n}+2} \mathrm{H}_{2}+\mathrm{H}\right)$ until they reach their maximum stable length. The thermodynamic stability of polyynes increases with higher temperatures whereas the stability of other hydrocarbons decreases [37]. Furthermore, large polyyne radicals can react with each other. We found polyynes up to $\mathrm{C}_{14} \mathrm{H}_{2}$ in the neat acetylene flame and with lower concentrations in the ethanol-doped flame as Fig. 8 shows. Their ionization energy decreases monotonically with their chain length and can be found for $\mathrm{C}_{4} \mathrm{H}_{2}, \mathrm{C}_{6} \mathrm{H}_{2}$, and $\mathrm{C}_{8} \mathrm{H}_{2}$ in the NIST database [40]. In recent studies, ionization energies for polyynes up to $\mathrm{C}_{18} \mathrm{H}_{2}$ were experimentally determined or calculated [15,41,42]. These values are in good agreement with our results as shown in Table S2 in supplemental material. In Fig. 8 the maximum mole fractions for the polyynes from $\mathrm{C}_{4} \mathrm{H}_{2}$ up to $\mathrm{C}_{14} \mathrm{H}_{2}$ are plotted in logarithmic scale against the number of carbon atoms in the molecule and show that the peak concentrations nearly exponentially decrease with the chain length of the polyynes. In other words, the concentration ratio of $\mathrm{C}_{2 \mathrm{n}} \mathrm{H}_{2} / \mathrm{C}_{2 \mathrm{n}-2} \mathrm{H}_{2}$ should be constant, as previously concluded by Li et al. [15]. These observations can help to improve existing models to consider the formation of higher polyynes. Especially, the small polyynes diacetylene $\left(\mathrm{C}_{4} \mathrm{H}_{2}\right)$ and hexatriyne $\left(\mathrm{C}_{6} \mathrm{H}_{2}\right)$ are detectable in higher concentrations in the exhaust gas zone than all other intermediate species. This observation is due to the fact that acetylene itself is not consumed completely under fuel-rich conditions and still promotes the formation of the polyynes. The experimental data and the modeling results indicate a decrease of the mole fractions of polyynes for the ethanol-doped flame in agreement with the trend for $\mathrm{C}_{4} \mathrm{H}_{2}$ and $\mathrm{C}_{6} \mathrm{H}_{2}$ in the simulation. The model does not consider the formation of higher polyynes than $\mathrm{C}_{6} \mathrm{H}_{2}$.

Similar conclusions as for the polyynes can derived for the polyynic compounds $\mathrm{C}_{n} \mathrm{H}_{4}(\mathrm{n} \geq 4)$ which were detected up to $\mathrm{C}_{11} \mathrm{H}_{4}$. To our knowledge, $\mathrm{C}_{11} \mathrm{H}_{4}$ was not detected before in an acetylene flame. Again, there is an almost exponential correlation between the maximum mole fractions of the different $\mathrm{C}_{n} \mathrm{H}_{4}$ species as shown in Fig. 8. However, it must be considered that for large polyynic $\mathrm{C}_{n} \mathrm{H}_{4}$ intermediates, no measured photoionization cross sections are available and the 8 
error of the concentrations can be large. Overall, both the concentration of polyynes and polyynic intermediates decrease with the substitution of $10 \%$ acetylene by ethanol. From Fig. 8 it follows that the relative decrease in mole fraction increases with the number of carbon atoms and that the mole fractions of large polyyne and polyynic $\mathrm{C}_{n} \mathrm{H}_{4}$ are affected stronger by the addition of ethanol.

In previous measurements of rich acetylene flames [12,15], the signal of $m / z=66$ was attributed to $\mathrm{C}_{5} \mathrm{H}_{6}$. However, the existence of $\mathrm{C}_{4} \mathrm{H}_{2} \mathrm{O}$ could not be excluded [13]. Here, we observed two peaks in the mass spectra for mass 66 with peak maxima at different burner positions clearly identified as $\mathrm{C}_{5} \mathrm{H}_{6}$ and $\mathrm{C}_{4} \mathrm{H}_{2} \mathrm{O}$. A more detailed identification of isomers can be done by PIE spectra. Figure 9 gives a comparison of the measured PIE curve for $\mathrm{C}_{5} \mathrm{H}_{6}$ with the Franck-Condon calculations for 1,3-cyclopentadiene and 3-penten-1-yne obtained from [43]. The weighted sum of both isomers fits the measured PIE curve of the doped flame well at a HAB of $4.5 \mathrm{~mm}$ and predicts a ratio of 75:25. The onsets match the ionization potentials.

There are five possible $\mathrm{C}_{4} \mathrm{H}_{2} \mathrm{O}$ isomers whose ionization energies and PIE curves were calculated by Kasper et al. [44]. The Franck-Condon simulations of two possible isomers (HCCCHCO and $\mathrm{H}_{2} \mathrm{CCCCO}$ ) and the measured PIE curve are shown in Fig. 10. The small onset at about $8.61 \mathrm{eV}$ could be caused by $\mathrm{H}_{2} \mathrm{CCCCO}$, which has a calculated adiabatic ionization energy of $8.66 \mathrm{eV}$. The next onset fits the most stable $\mathrm{C}_{4} \mathrm{H}_{2} \mathrm{O}$ isomer [42], HCCCHCO, that can be formed by reaction of diacetylene with $\mathrm{OH}$ radical [45]. The species assignment is therefore different from [44] where $\mathrm{H}_{2} \mathrm{CCCCO}$ was the most likely isomer in a THF flame. The identification can help to understand the oxidation pathways of small polyynes under fuel-rich conditions.

\section{Conclusions}

A slightly sooting, premixed flat acetylene flame with a stoichiometry of $\phi=2.4$ at low pressure (40 mbar) was investigated by MBMS in combination with VUV photoionization at the ALS and the SLS. The effect of ethanol addition to the neat acetylene flame was studied with regard to soot precursors. Ethanol addition results in a decrease of the soot precursor propargyl $\left(\mathrm{C}_{3} \mathrm{H}_{3}\right)$, benzene $\left(\mathrm{C}_{6} \mathrm{H}_{6}\right)$, and the polyynes. From the reduction of soot precursor concentration, a degradation of soot due to the addition of ethanol can be inferred. Otherwise, the addition of ethanol leads to an increase of oxygenated hydrocarbons like aldehydes.

Mole-fraction profiles of over 50 species were calculated and compared with initial modeling results. The good agreement for major species and several intermediate species confirms the high quality of the presented data set. These experimental results give a detailed survey of the flame structure and can help to improve future kinetic models. 


\section{Acknowledgments}

TB and TK are grateful for financial support from MIWF. All measurements were performed at the ALS and the SLS, respectively. The Advanced Light Source is supported by the Director, Office of Science, Office of Basic Energy Sciences, of the U.S. Department of Energy under Contract No. DE-AC02-05CH11231. The work was financially supported by the Swiss Federal Office for Energy (BFE Contract Number 101969/152433). The research leading to these results has received funding from the European Community's Seventh Framework Programme (FP7/2007-2013) under grant agreement $n^{\circ}$ 312284. AL is supported by the US Department of Energy, Office of Basic Energy Sciences (BES) under Grand No. DE-SC0001198 (the Combustion Energy Frontier Research Center). We appreciate support and helpful discussions from Ahren Jasper, Nils Hansen, Phil Westmoreland, Katharina Kohse-Höinghaus and all other members of the ALS and SLS flame team.

\section{References}

[1] M. Balat, H. Balat, Appl. Energy 86 (2009) 2273-2282.

[2] C. Esarte, Á. Millera, R. Bilbao, M.U. Alzueta, Ind. Eng. Chem. Res. 49 (2010) 6772-6779.

[3] I.E. Gerasimov, D.A. Knyazkov, S.A. Yakimov, T.A. Bolshova, A.G. Shmakov, O.P. Korobeinichev, Combust. Flame 159 (2012) 1840-1850.

[4] D. Golea, Y. Rezgui, M. Guemini, S. Hamdane, J. Phys. Chem. A 116 (2012) 3625-3642.

[5] M.M. Maricq, Combust. Flame 159 (2012) 170-180.

[6] M. Frenklach, Phys. Chem. Chem. Phys. 4 (2002) 2028-2037.

[7] H. Böhm, A. Lamprecht, B. Atakan, K. Kohse-Höinghaus, Phys. Chem. Chem. Phys. 2 (2000) 4956-4961.

[8] H. Richter, J.B. Howard, Prog. Energy Combust. Sci. 26 (2000) 565-608.

[9] A.V. Krestinin, Combust. Flame 121 (2000) 513-524.

[10] C. Yao, X. Yang, R.R. Raine, C. Cheng, Z. Tian, Y.Li, Energy Fuels 23 (2009) 3543-3548.

[11] C. Douté, J.-L. Delfau, C. Vovelle, Combust. Sci. and Tech. 103 (1994) 153-173.

[12] A. Lamprecht, B. Atakan, K. Kohse-Höinghaus, Combust. Flame 122 (2000) 483-491.

[13] P.R. Westmoreland, Experimental and theoretical analysis of oxidation and growth chemistry in a fuel-rich acetylene flame, PhD thesis, Massachusetts Institute of Technology, Cambridge, USA, 1986.

[14] R. Ancia, P.J. Van Tiggelen, J. Vandooren, Exp. Therm. Fluid Sci. 28 (2004) 715-722.

[15] Y. Li, L. Zhang, Z. Tian, T. Yuan, K. Zhang, B. Yang, F. Qi, Proc. Combust. Inst. 32 (2009) 1293-1300.

[16] P.R. Westmoreland, W. Li, N. Hansen, T. Kasper, T.A. Cool, A. Lucassen, K. Kohse-Höinghaus, Proceedings of the $6^{\text {th }}$ US National Combustion Meeting 3 (2009) 1401-1406. 
[17] T. Kasper, U. Struckmeier, P. Oßwald, K. Kohse-Höinghaus, Proc. Combust. Inst. 32 (2009) 1285-1292.

[18] N. Hansen, T.A. Cool, P.R. Westmoreland, K. Kohse-Höinghaus, Prog. Energy Combust. Sci. 35 (2009) 168-191.

[19] P. Oßwald, P. Hemberger, T. Bierkandt, E. Akyildiz, M. Köhler, A. Boedi, T. Gerber, T. Kasper, Rev. Sci. Instrum. (Accepted 2013).

[20] A. Bodi, P. Hemberger, T. Gerber, B. Sztaray, Rev. Sci. Instrum. 83 (2012) 083105.

[21] A. Bodi, M. Johnson, T. Gerber, Z. Gengeliczki, B. Sztaray, T. Baer, Rev. Sci. Instrum. 80 (2009) 034101.

[22] T.A. Cool, K. Nakajima, C.A. Taatjes, A. Mcllroy, P.R. Westmoreland, M.E. Law, A. Morel, Proc. Combust. Inst. 30 (2005) 1681-1688.

[23] C.A. Taatjes, N. Hansen, J.A. Miller, T.A. Cool, J. Wang, P.R. Westmoreland, M.E. Law, T. Kasper, K. KohseHöinghaus, J. Phys. Chem. A 110 (2006) 3254-3260.

[24] N. Hansen, J.A. Miller, T. Kasper, K. Kohse-Höinghaus, P.R. Westmoreland, J. Wang, T.A. Cool, Proc. Combust. Inst. 32 (2009) 623-630.

[25] J. Wang, U. Struckmeier, B. Yang, T.A. Cool, P. Osswald, K. Kohse-Höinghaus, T. Kasper, N. Hansen, P.R. Westmoreland,, J. Phys. Chem. A 112 (2008) 9255-9265.

[26] N.J. Labbe V. Seshadri, T. Kasper, N. Hansen, P. Oßwald, P.R. Westmoreland, Proc. Combust. Inst. 34 (2013) 259267.

[27] H. Richter, J.B. Howard, Phys. Chem. Chem. Phys. 4 (2002) 2038-2055.

[28] J.D. Savee, S. Soorkia, O. Welz, T.M. Selby, C.A. Taatjes, D.L. Osborn, J. Chem. Phys. 136 (2012) 134307.

[29] P. Botschwina, R. Oswald, Chem. Phys. 378 (2010) 4-10.

[30] P. Hemberger, M. Lang, B. Noller, I. Fischer, C. Alcaraz, B.K. Cunha de Miranda, G.A. Garcia, H. Soldi-Lose, J. Phys. Chem. A 115 (2011) 2225-2230.

[31] C.L. Rasmussen, M.S. Skjoth-Rasmussen, A.D. Jensen, P. Glarborg, Proc. Combust. Inst. 30 (2005) $1023-1031$.

[32] H. Wang, M. Frenklach, Combust. Flame 110 (1997) 173-221.

[33] N. Hansen, S.J. Klippenstein, C.A. Taatjes, J.A. Miller, J. Wang, T.A. Cool, B. Yang, R. Yang, L. Wei, C. Huang, J. Wang, F. Qi, M.E. Law, P.R. Westmoreland, J. Phys. Chem. A 110 (2006) 3670-3678.

[34] S. Soorkia, A.J. Trevitt, T.M. Selby, D.L. Osborn, C.A. Taatjes, K.R. Wilson, S.R. Leone, J. Phys. Chem. A 114 (2010) 3340-3354.

[35] T.A. Cool, J. Wang, K. Nakajima, C.A. Craig, A. Mcllroy, Int. J. Mass Spectrom. 247 (2005) 18-27.

[36] G. Blanquart, P. Pepiot-Desjardins, H. Pitch, Combust. Flame 156 (2009) 588-607.

[37] A.V. Krestinin, M.B. Kislov, A.V. Raevskii, O.I. Kolesova, L.N. Stesik, Kinet. Catal. 41 (2000) 90-98.

[38] T. Schüßler, H.-J. Deyerl, S. Dümmler, I. Fischer, C. Alcaraz, J. Chem. Phys. 118 (2003) 9077-9080. 
[39] C.A. Taatjes, S.J. Klippenstein, N. Hansen, J.A. Miller, T.A. Cool, J. Wang, M.E. Law, P.R. Westmoreland, Phys. Chem. Chem. Phys. 7 (2005) 806-813.

[40] P.J. Linstrom, W.G. Mallard, Eds., NIST Chemistry WebBook, NIST Standard Reference Database Number 69, National Institute of Standards and Technology, Gaithersburg MD, 20899, http://webbook.nist.gov, (retrieved May 7, 2014).

[41] N. Hansen, S.J. Klippenstein, P.R. Westmoreland, T. Kasper, K. Kohse-Höinghaus. J. Wang, T.A. Cool, Phys. Chem. Chem. Phys. 10 (2008) 366-374.

[42] R.I. Kaiser, B.J. Sun, H.M. Lin, A.H.H. Chang, A.M. Mebel, O. Kostko, M. Ahmed, Astrophys. J. 719 (2010) 18841889.

[43] N. Hansen, S.J. Klippenstein, J.A. Miller, J. Wang, T.A. Cool, M.E. Law, P.R. Westmoreland, T. Kasper, K. KohseHöinghaus, J. Phys. Chem. A 110 (2006) 4376-4388.

[44] T. Kasper, A. Lucassen, A.W. Jasper, W. Li, P.R. Westmoreland, K. Kohse-Höinghaus, B. Yang, J. Wang, T.A. Cool, N. Hansen, Z. Phys. Chem. 225 (2011) 1237-1270.

[45] J.P. Senosiain, S.J. Klippenstein, J.A. Miller, Proc. Combust. Inst. 31 (2007) 185-192.

\section{Figures}
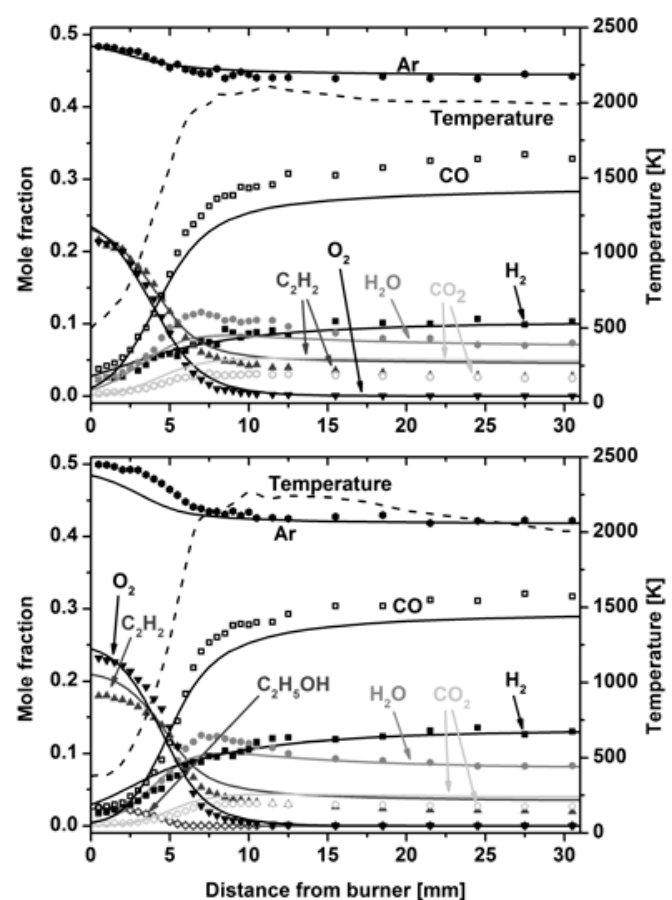

Figure 1. Temperature profiles and mole fraction profiles of the major species in the pure acetylene flame (top) and in the acetylene flame doped with ethanol (bottom). Symbols: experiment, lines: modeling. 

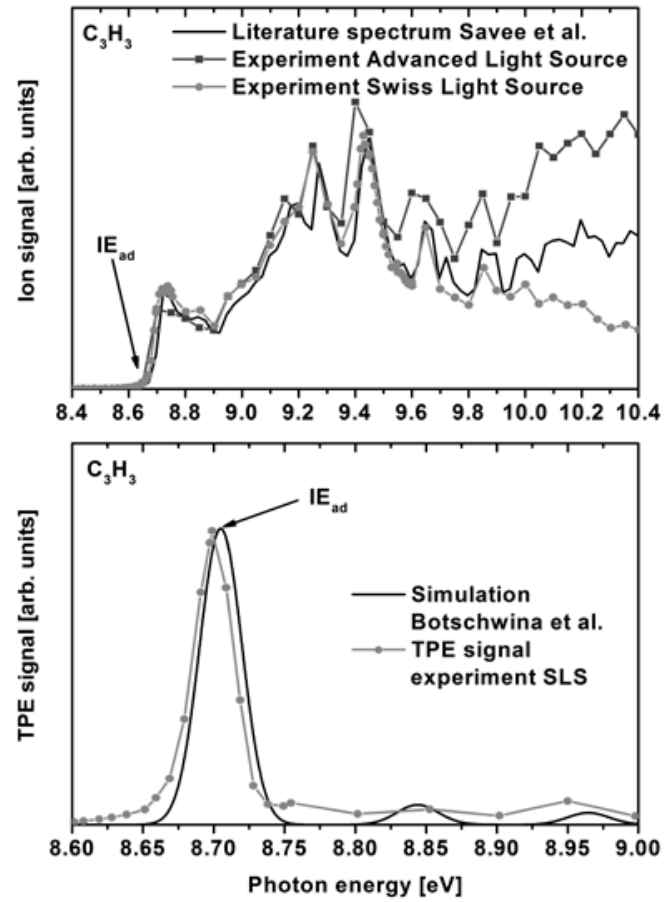

Figure 2. PIE (top) and mass-selected TPE spectra (bottom) of the propargyl radical measured in an acetylene flame compared to a literature spectra and a Franck-Condon Simulation, respectively.

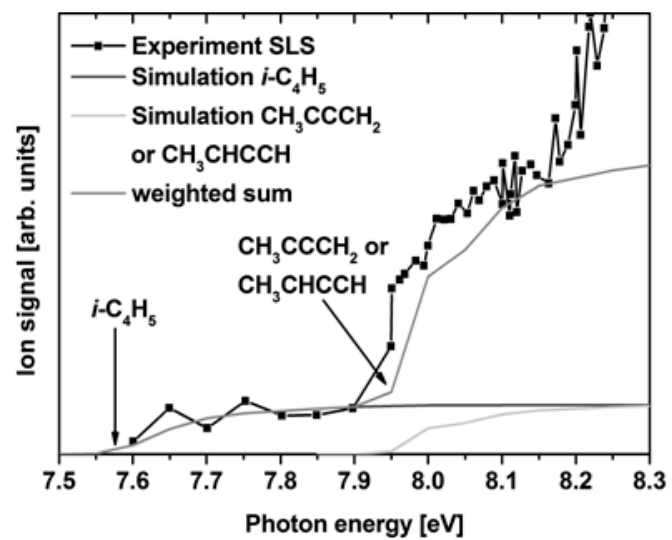

Figure 3. Comparison of Franck-Condon simulation for photoionization of $\mathrm{C}_{4} \mathrm{H}_{5}$ isomers from [32] with experimental data obtained from acetylene flame measurements at the SLS. 

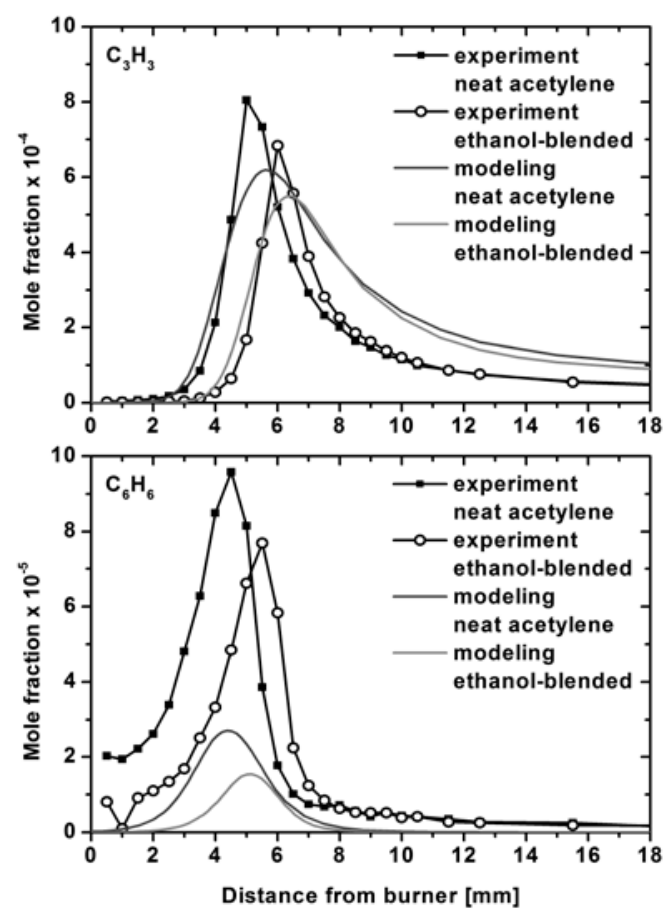

Figure 4. Comparison of measured mole fraction profiles of propargyl and benzene at the ALS with modeling results.

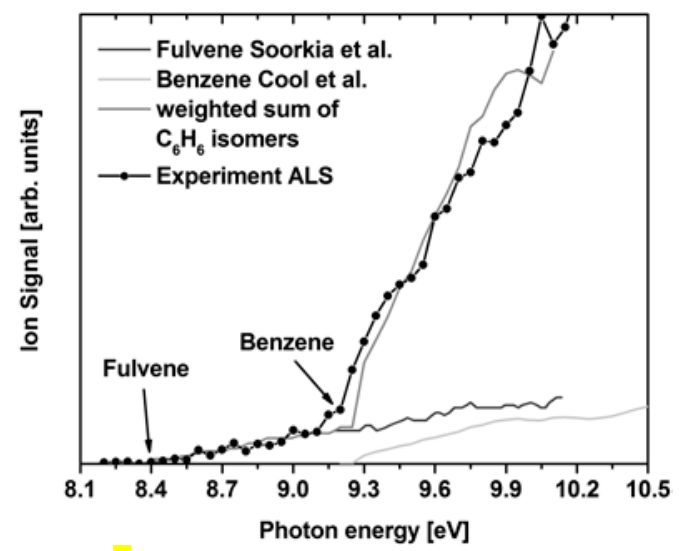

Figure 5. Identification of benzene and fulvene in the pure acetylene flame by comparison of literature cross sections between 8.2 and $10.2 \mathrm{eV}$ with the measured PIE curve.

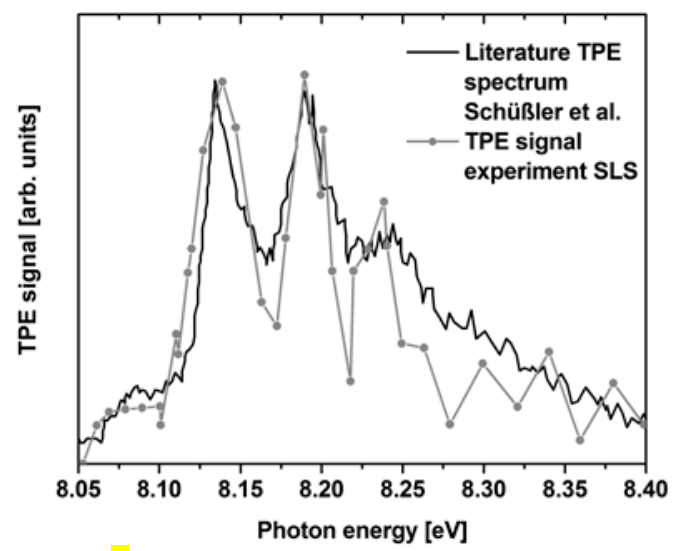

Figure 6. Identification of allyl radical in the acetylene flame by threshold photoelectron spectroscopy. 


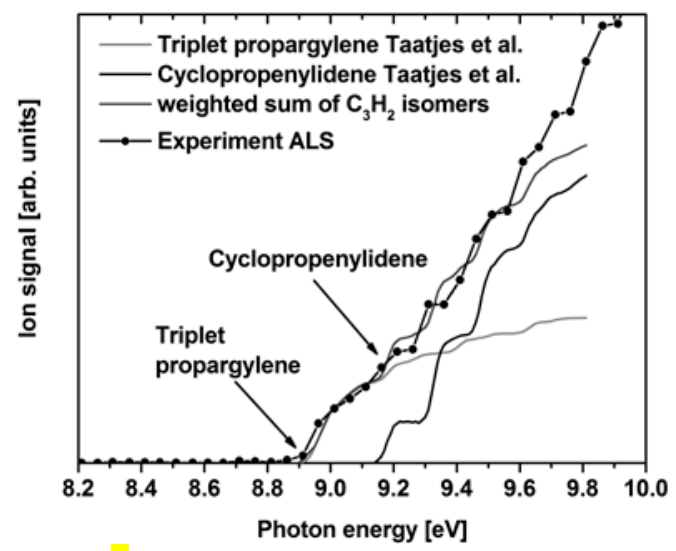

Figure 7. Identification of $\mathrm{C}_{3} \mathrm{H}_{2}$ isomers in the pure acetylene flame by comparison of Franck-Condon simulations with the measured PIE curve.

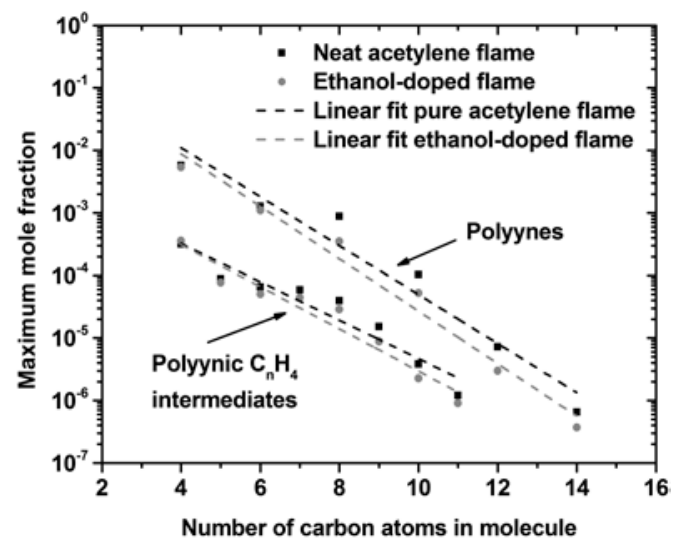

Figure 8. Maximum mole fractions of polyynes and polyyinic $\mathrm{C}_{n} \mathrm{H}_{4}$ intermediates in fuel-rich acetylene and ethanoldoped flame measured at the ALS.

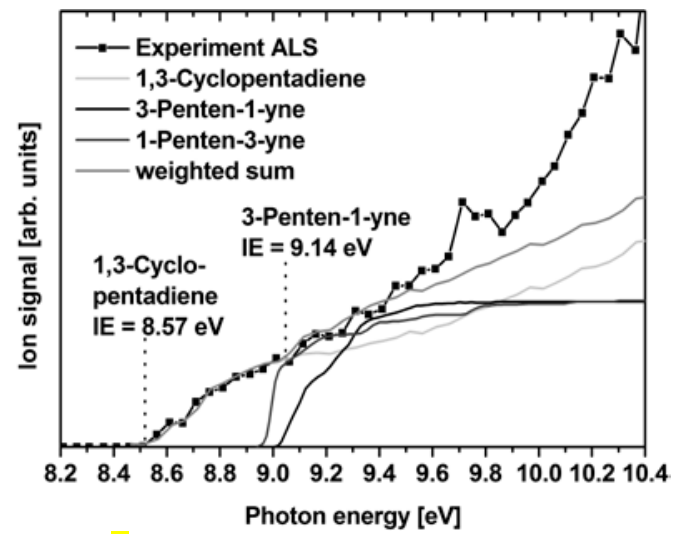

Figure 9. Comparison of PIE curve for $m / z=66\left(\mathrm{C}_{5} \mathrm{H}_{6}\right)$ from the ethanol-doped flame to Franck-Condon simulations of $\mathrm{C}_{5} \mathrm{H}_{6}$ isomers from [41].

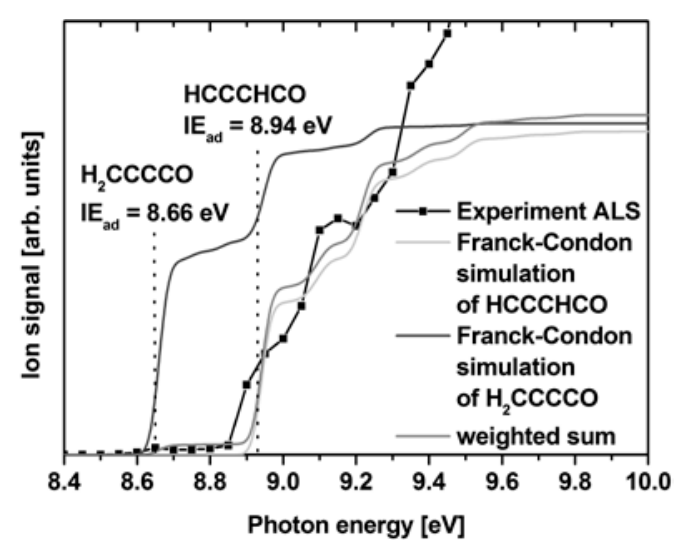


Figure 10. Comparison of experimental PIE curve from pure acetylene flame measured at $6.5 \mathrm{~mm}$ to the Franck-Condon simulations of $\mathrm{C}_{4} \mathrm{H}_{2} \mathrm{O}$ isomers from [42]. 
List of figure captions:

Figure 1. Temperature profiles and mole fraction profiles of the major species in the pure acetylene flame (top) and in the acetylene flame doped with ethanol (bottom). Symbols: experiment, lines: modeling.

Figure 2. PIE (top) and mass-selected TPE spectra (bottom) of the propargyl radical measured in an acetylene flame compared to a literature spectra and a Franck-Condon Simulation, respectively.

Figure 3. Comparison of Franck-Condon simulation for photoionization of $\mathrm{C}_{4} \mathrm{H}_{5}$ isomers from [32] with experimental data obtained from acetylene flame measurements at the SLS.

Figure 4. Comparison of measured mole fraction profiles of propargyl and benzene at the ALS with modeling results.

Figure 5. Identification of benzene and fulvene in the pure acetylene flame by comparison of literature cross sections between 8.2 and $10.2 \mathrm{eV}$ with the measured PIE curve.

Figure 6. Identification of allyl radical in the acetylene flame by threshold photoelectron spectroscopy.

Figure 7. Identification of $\mathrm{C}_{3} \mathrm{H}_{2}$ isomers in the pure acetylene flame by comparison of Franck-Condon simulations with the measured PIE curve.

Figure 8. Maximum mole fractions of polyynes and polyyinic $\mathrm{C}_{n} \mathrm{H}_{4}$ intermediates in fuel-rich acetylene and ethanoldoped flame measured at the ALS.

Figure 9. Comparison of PIE curve for $m / z=66\left(\mathrm{C}_{5} \mathrm{H}_{6}\right)$ from the ethanol-doped flame to Franck-Condon simulations of $\mathrm{C}_{5} \mathrm{H}_{6}$ isomers from [41].

Figure 10. Comparison of experimental PIE curve from pure acetylene flame measured at $6.5 \mathrm{~mm}$ to the Franck-Condon simulations of $\mathrm{C}_{4} \mathrm{H}_{2} \mathrm{O}$ isomers from [42]. 

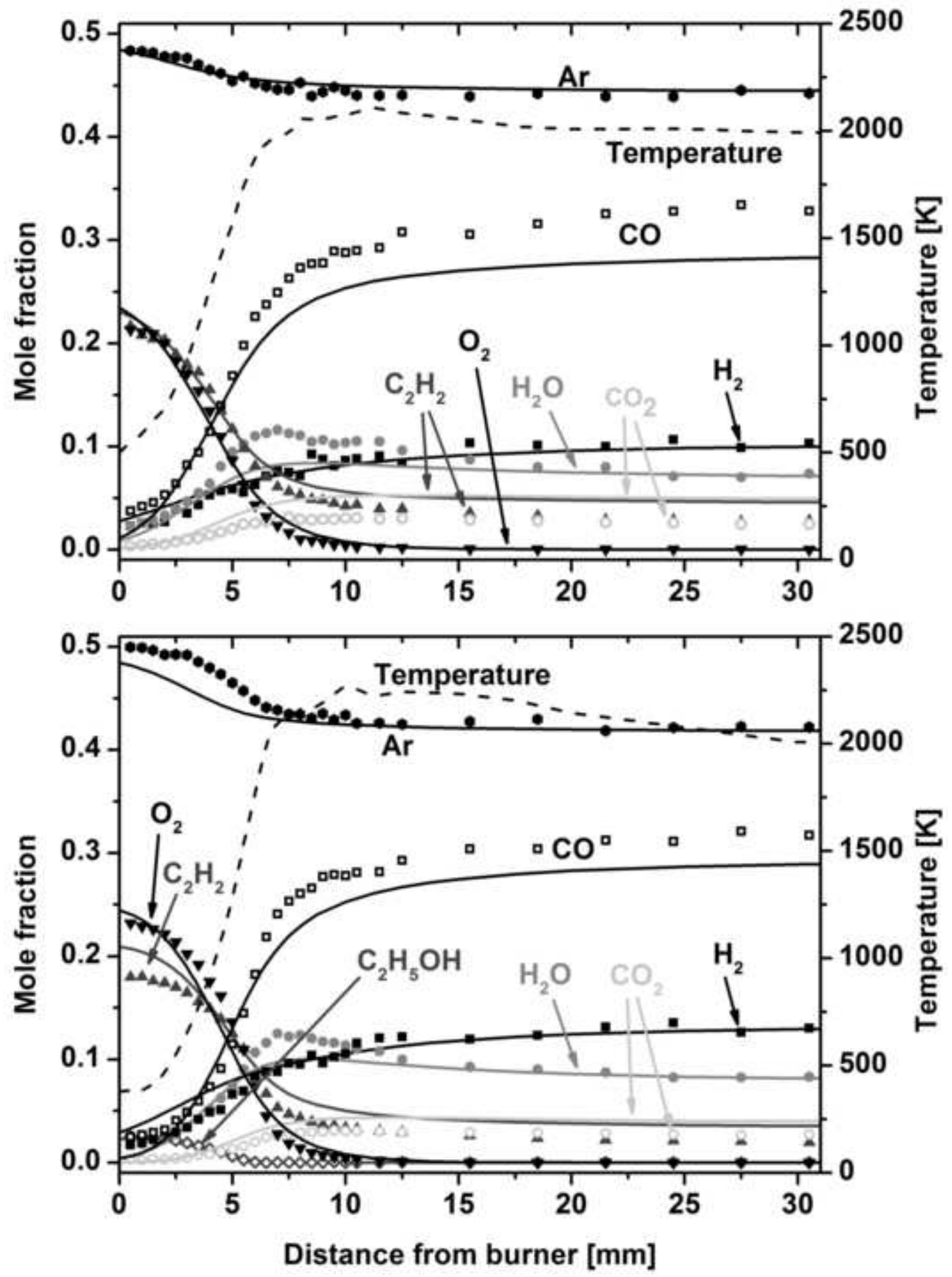

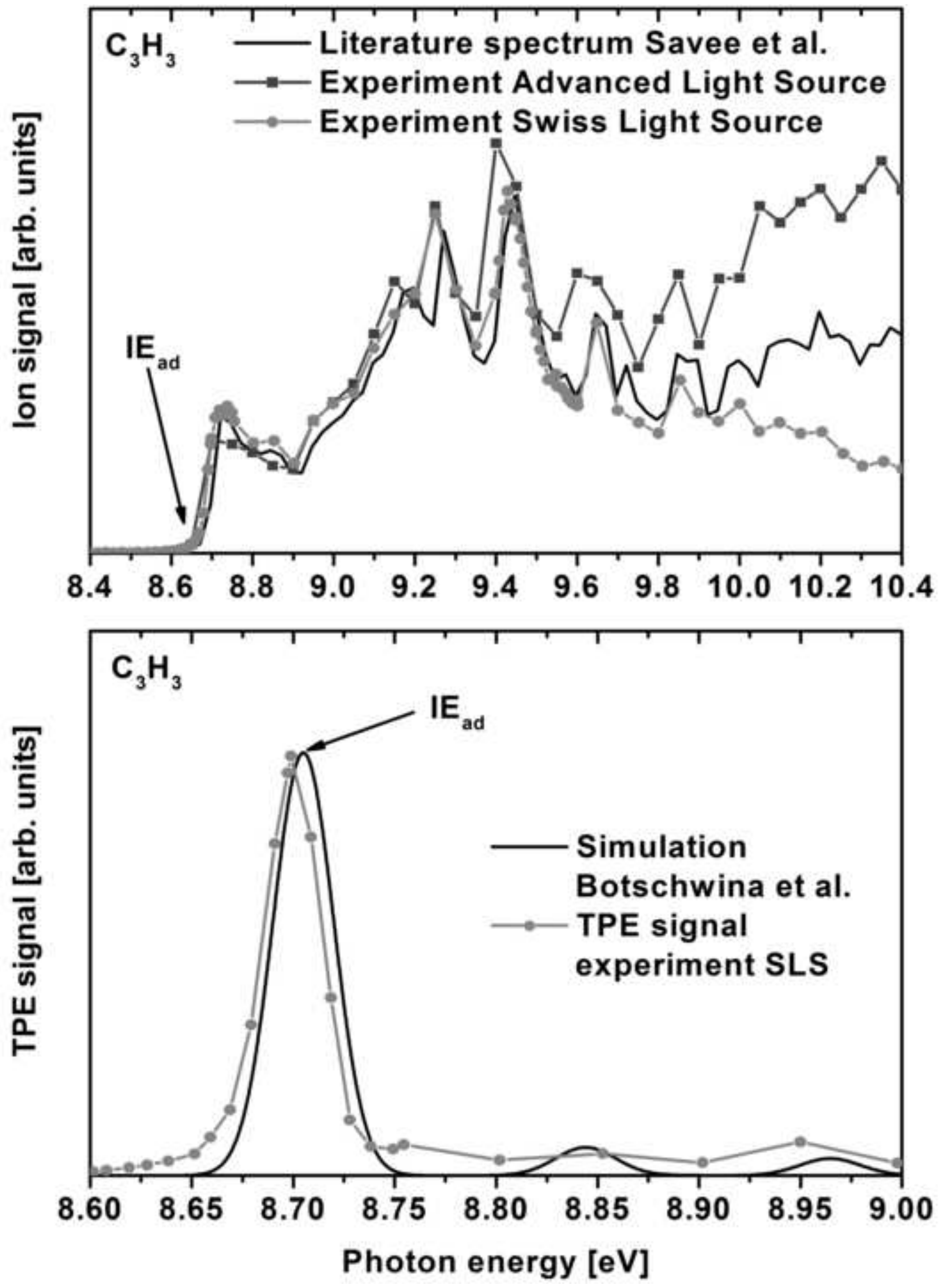


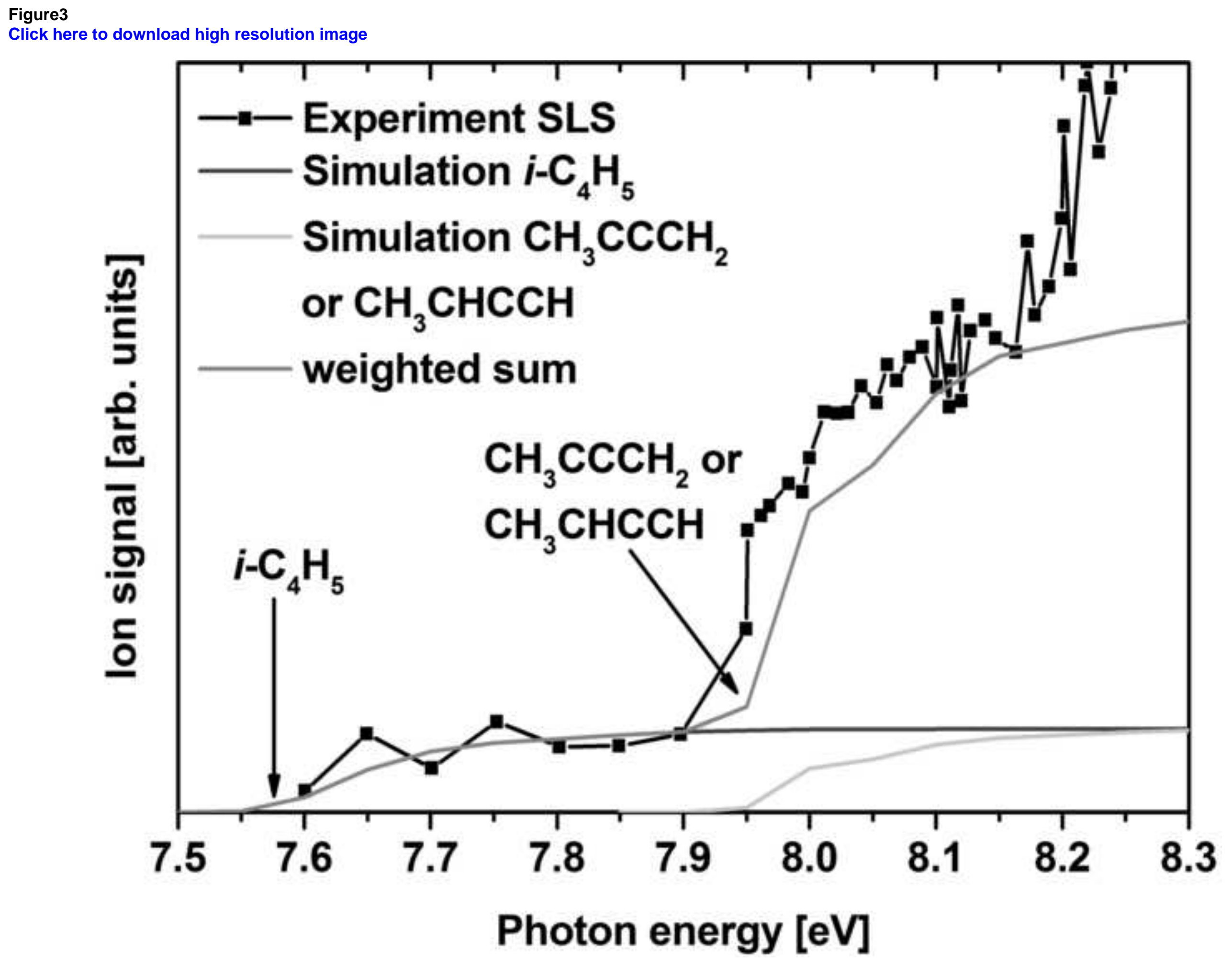


Click here to download high resolution image
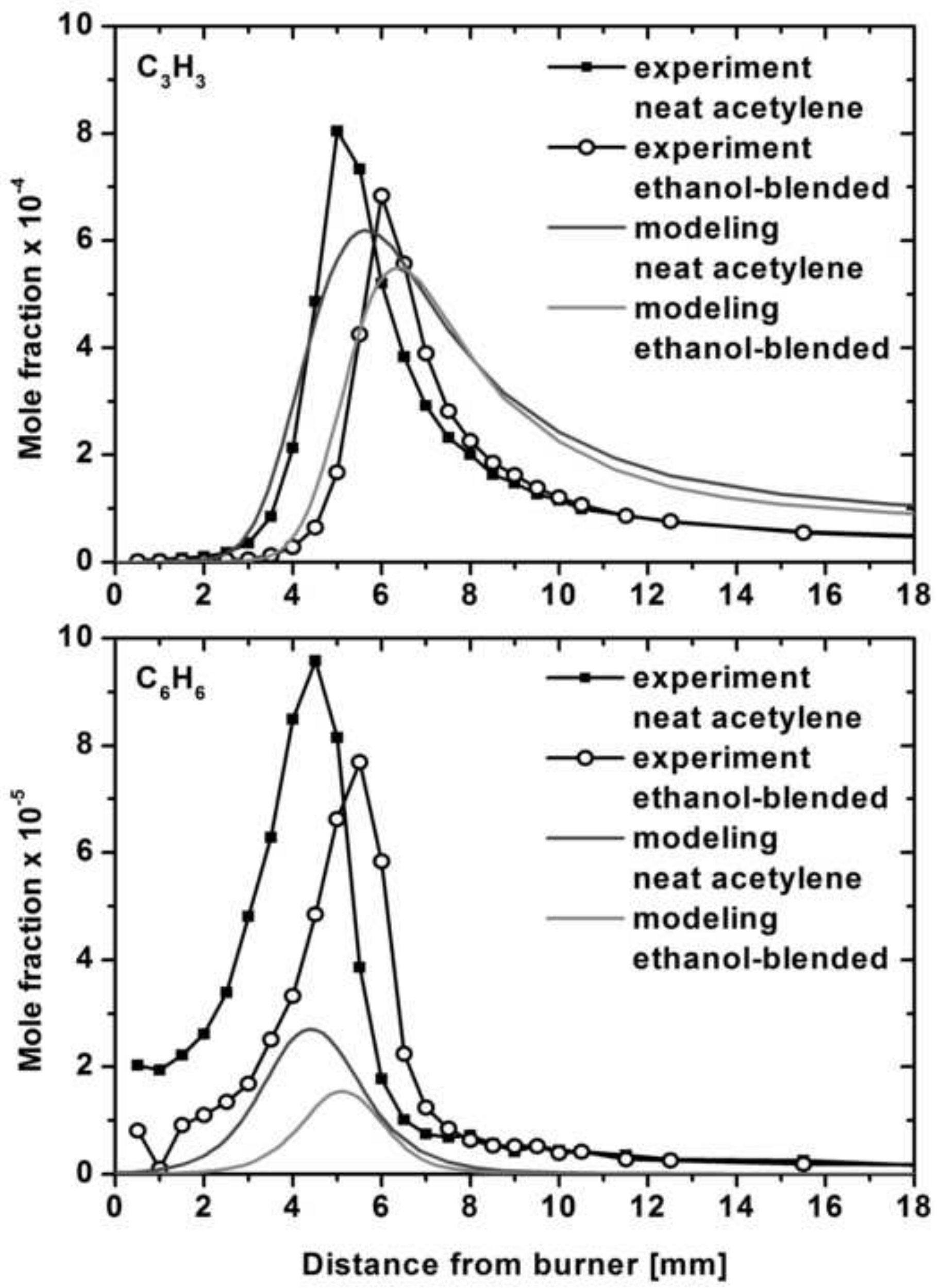


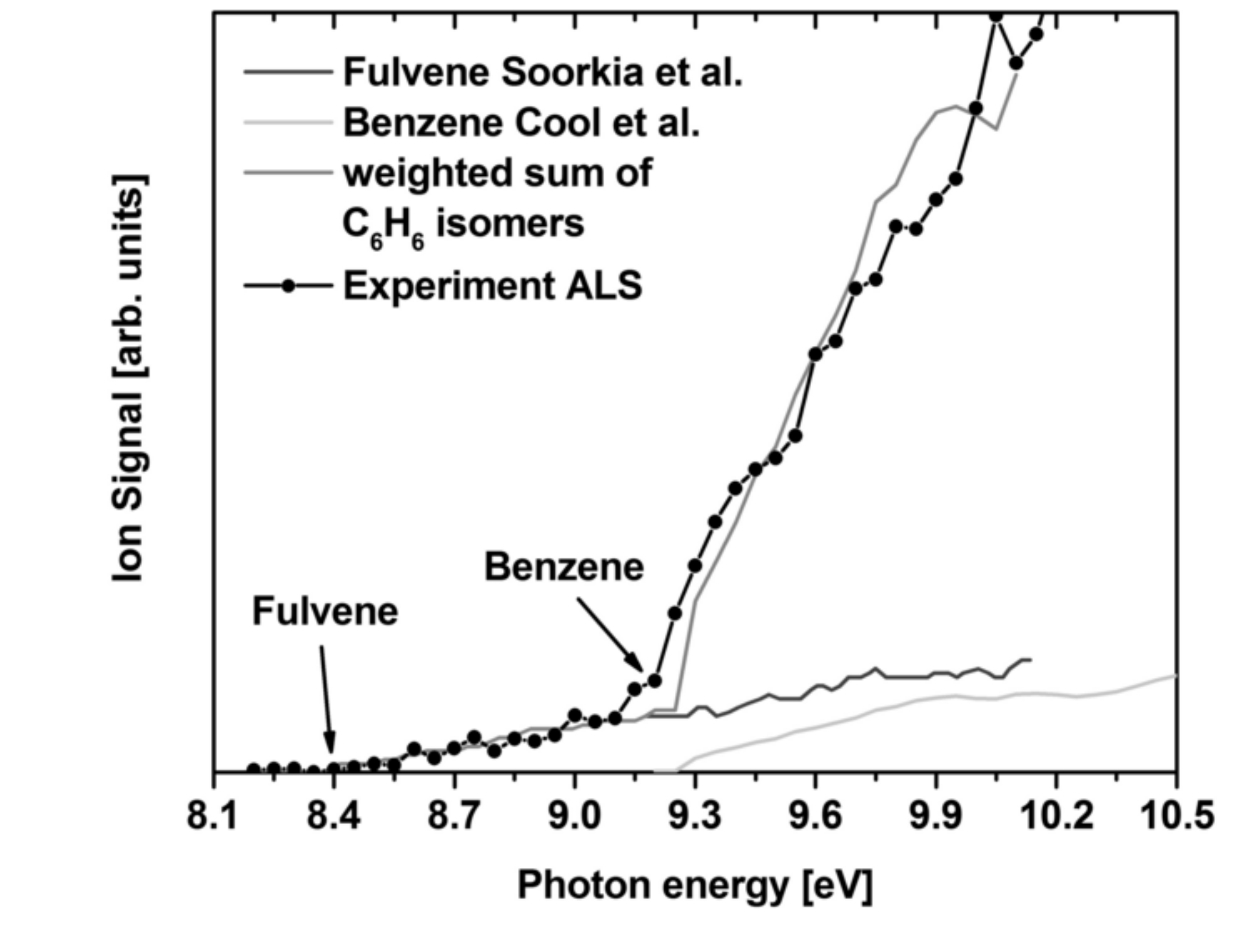

.

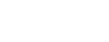

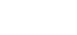

.

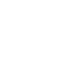




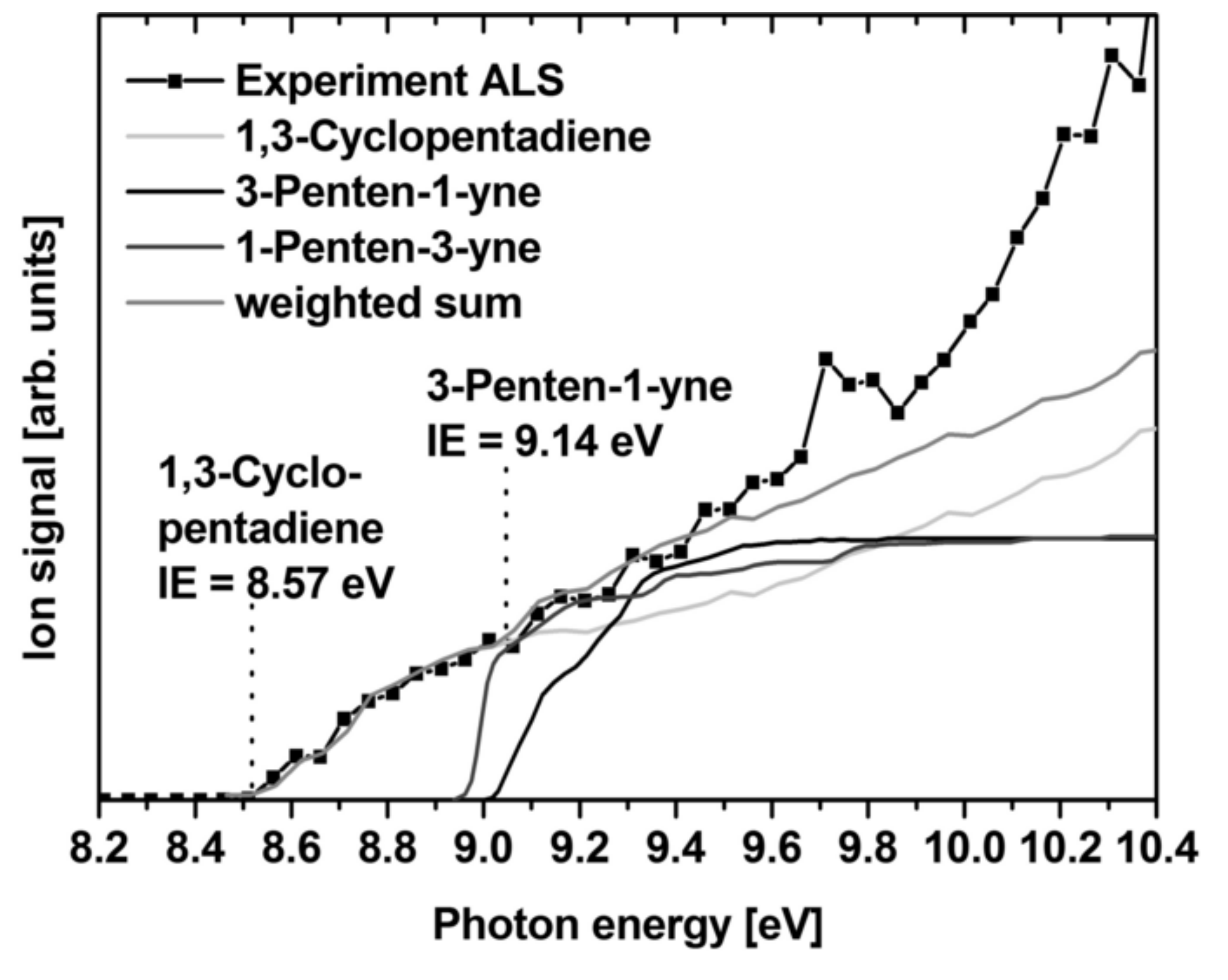




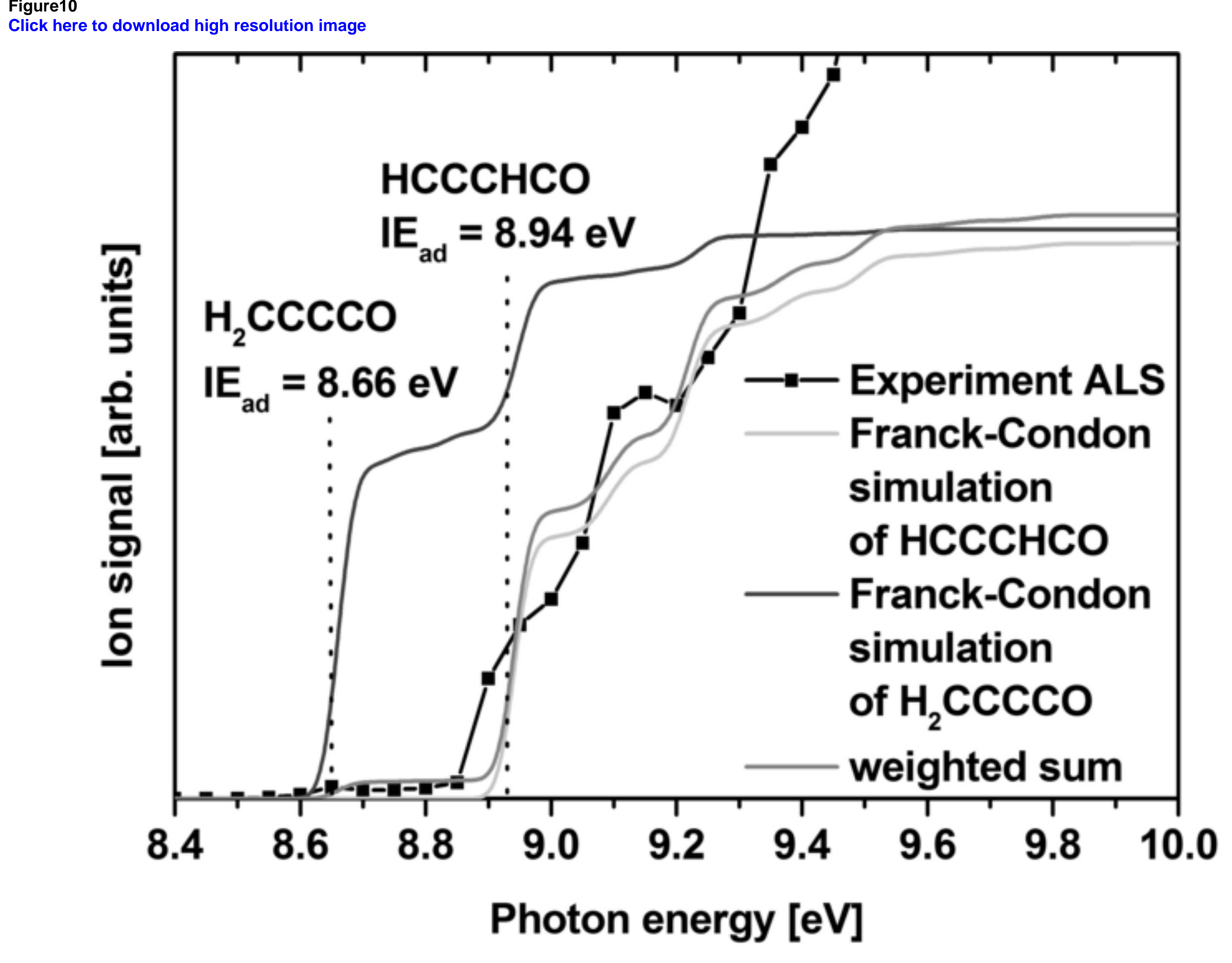

